\title{
An hypothesis regarding the origin of aneuploidy in man: indirect evidence from an experimental model
}

\author{
M H KAUFMAN* \\ From the Department of Anatomy, University of Cambridge, Downing Street, Cambridge CB2 3DY.
}

SUMMARY Recent studies have clearly demonstrated that aneuploidy may be induced in about 10 to $20 \%$ of oocytes and recently ovulated eggs when female mice are given an intragastric injection of a dilute solution of ethanol. Similar rates of aneuploidy have also been observed when recently ovulated eggs are briefly exposed in vitro to a dilute solution of ethanol in tissue culture medium. These findings are briefly reviewed, and observations made on the possible underlying mechanism of induction of chromosome malsegregation in the ethanol exposed groups. Attention is drawn to evidence from a wide range of studies on the effect of ethanol, acetaldehyde (its primary metabolite), and anaesthetics on cell division and chromosome segregation in an attempt to substantiate an hypothesis regarding the mode of action of these agents. In the light of this information, it is hypothesised that exposure to ethanol probably interferes with the normal functioning of the cytoskeletal elements of the spindle apparatus, or its precursor elements, during the first or second meiotic divisions. An attempt is also made to account for the very high incidence of aneuploid conceptuses in man, a high proportion of which are spontaneously aborted. It is hypothesised that exposure to ethanol and other spindle active agents during appropriate stages of oogenesis (in particular during the first meiotic division), and possibly also during spermatogenesis, may be important aetiological factors in a proportion of those cases of spontaneous abortion with a numerical chromosome anomaly for which no other obvious cause is recognised. It is already well established that exposure to alcohol during human pregnancy may be harmful to the conceptus. If it is valid to extrapolate from these experimental findings to the clinical situation in man, it is suggested that attention should also be drawn to the potentially greater hazard to the conceptus which could result from maternal alcohol consumption at and shortly before conception.

Quite recently, a series of reports have clearly demonstrated that ethanol is capable of inducing malsegregation of meiotic chromosomes during the first and second meiotic divisions in mice, when exposure of female gametes to ethanol occurs during the cycle before ovulation ${ }^{12}$ or at the time of conception. ${ }^{3}$

These observations have led this author to speculate on the possible underlying mechanism of induction of aneuploidy in the ethanol exposed groups of gametes, and to consider whether it might be valid to extrapolate from these observations in

\footnotetext{
*Present address: Department of Anatomy, University Medical School, Teviot Place, Edinburgh EH8 9AG.

Received for publication 19 November 1984. Accepted for publication 6 December 1984.
}

the mouse to the clinical situation in man.

In these studies, unmated females were exposed to ethanol at various times in relation to the human chorionic gonadotrophin (HCG) injection for inducing ovulation. The females were lightly anaesthetised with ether and a dilute solution of ethanol in distilled water was introduced via a fine plastic tube passed into the stomach. The mice were then mated and their embryos subsequently recovered and analysed either at the first cleavage mitosis or at the morula stage. The air drying technique employed, ${ }^{4}$ in which pronuclear stage 1 cell eggs were incubated in tissue culture medium containing colcemid, allowed the eggs at this stage of development to progress to metaphase of the first cleavage mitosis, but, more importantly, allowed the male and female 
pronuclear chromosome sets to remain as two discrete groups. In some of these experiments, the males carried an appropriate 'marker' chromosome which enabled the maternal and paternal chromosome sets to be distinguished. It transpired that aneuploidy had in fact been induced in a proportion of the female derived, but apparently not in the male derived, pronuclear sets of chromosomes. In these investigations, the incidence of aneuploidy was $19 \%$ and $13.5 \%$ at the first cleavage and morula stages, respectively, in the in vivo exposed groups. ${ }^{1-3}$ Parallel studies were also carried out in which ethanol induced parthenogenetically activated haploid mouse eggs induced in vitro were analysed at the first cleavage mitosis. In this series, the incidence of aneuploidy ranged from 14 to $19 \%$ in the various ethanol exposed groups. ${ }^{5}$

A wide variety of other chemical and physical stimuli are capable of inducing mammalian eggs to undergo parthenogenetic activation, but the cytogenetic analyses of large numbers of parthenogenetically activated eggs and embryos have revealed that parthenogenesis per se is not normally associated with the induction of errors of chromosome segregation. ${ }^{6}$ It appears likely therefore that exposure to the ethanol in both the fertilised and parthenogenetically activated groups led to the production of aneuploid embryos. While the exact mode and site of action of ethanol in these studies has yet to be established, strong circumstantial evidence will be presented which suggests that it probably acts on the cytoskeletal elements of the spindle apparatus or on its precursor elements.

In an attempt to substantiate this hypothesis, evidence is drawn from a wide range of studies on the effect of ethanol, acetaldehyde (its primary metabolic product), and anaesthetics on cell division and chromosome segregation. In the light of these observations, it is suggested that the recent findings in the mouse may provide clues as to the aetiological factors involved in those cases of spontaneous abortion in man which possess an abnormal chromosome number.

As far as this author is aware, no adequate explanation has so far been proposed to account for the very high incidence of aneuploid conceptuses in man, ${ }^{78}$ most of which are spontaneously aborted. All that does appear to be certain is that these must result from a malsegregation event involving either the male or female gamete as these progress through the first or second meiotic division. Current information ${ }^{9}$ suggests that oocytes are considerably more vulnerable than spermatocytes in this regard, and that the malsegregation event is much more likely to occur during the first rather than the second meiotic division. The fact that spontaneous abor- tions occur throughout the reproductive life of the woman suggests that environmental (exogenous) rather than purely endogenous factors are the likely cause. It is hypothesised here that exposure to ethanol and other spindle active agents during appropriate stages of oogenesis, and possibly also during spermatogenesis, may be important aetiological agents in those cases of spontaneous abortion in man which possess a numerical chromosome anomaly for which no other obvious cause is recognised.

Possible mode of action of ethanol in inducing
aneuploidy

Numerous experimental studies have been carried out to investigate the teratogenicity of ethanol ${ }^{10-12}$ and acetaldehyde, ${ }^{13} 14$ but relatively little appears to be known about their effect on the chromosome constitution of either male or female germ cells. Some observers have reported that exposure to ethanol is capable of inducing numerical chromosome anomalies in spermatogonial mitoses in male rodents (mice, ${ }^{15}$ rats $^{16}$ ), and these findings appear to complement the recent reports on the effect of this agent on the chromosome constitution of oocytes as they progress through meiosis I and II. ${ }^{12} 5$

While the underlying mechanism of action of ethanol on male and female germ cells has yet to be established, a considerable number of reports are available on the effect of this and related agents on the chromosome constitution of mammalian cells in tissue culture (see below) as well as on plant cells. ${ }^{17} 18$

Much of the work on the effect of ethanol and $\overrightarrow{0}$ acetaldehyde on chromosomal structure and function has been carried out by Obe and his colleagues ${ }^{19-22}$ using a range of analytical techniques. ${ }^{23}$ While Obe is of the opinion that ethanol is mutagenic via its metabolite acetaldehyde others have claimed that under appropriate conditions ethanol itself may also be mutagenic.

The results obtained from mating male mice that had previously been exposed to repeated high levels $ᄋ$ of ethanol ${ }^{24}$ were tested by the dominant lethal $\tilde{O}$ assay, and the findings from this study, in which the N last ethanol dose had been given eight and 13 days before mating, indicated that chromosome defects 0

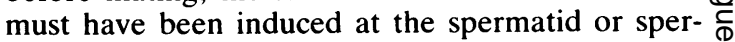
matozoon stage. Since additional experiments with $\stackrel{\oplus}{+}$ rats and subsequent experiments with mice pro- 0 duced no increase in the incidence of dominant lethals, the validity of the earlier findings was $\stackrel{\mathbb{D}}{\Omega}$ questioned. ${ }^{22}$ However, more recent studies in $\stackrel{\mathbb{Q}}{Q}$ which male rats were exposed to ethanol by mouth would appear to confirm the earlier observations on 
the mutagenicity of this agent at the spermatid stage of gametogenesis in the male as assessed by the dominant lethal assay. ${ }^{16}$ A single dose of a $40 \%$ solution of ethanol produced both numerical and structural anomalies of meiotic chromosomes, highest levels being observed when exposure occurred about two weeks before mating.

Studies with small lymphocytes from peripheral blood have also proved to be an instructive system for analysing the induction of chromosome damage. A rise in chromosome breaks has been reported following a four hour or 48 hour exposure period to $1.2 \%$ solution of ethanol, ${ }^{25}$ though these results have not been observed by others using similar doses of ethanol. Negative results have also been reported following the exposure of cultured human HeLa cells, mouse ascites tumour cells, and Chinese hamster cells to dilute solutions of ethanol. However, repeated exposure of Chinese hamster cells to dilute solutions of acetaldehyde resulted in an increase in the incidence of sister chromatid exchanges over control values. ${ }^{19} \mathrm{~A}$ higher mutagenic activity of acetaldehyde as compared to ethanol (that is, in that it induces higher rates of chromosome aberrations and sister chromatid exchanges) had previously been observed in plant material. ${ }^{26}$ Ethanol apparently had no chromosome breaking activity in root tips when roots were grown on bulbs, but aberrations were induced in root tips when these were grown from seeds in the presence of ethanol. ${ }^{27} 28$

It is clearly difficult to interpret these findings. It is equally unclear whether these observations are in any way related to the high incidence of chromosome damage seen in alcoholics. ${ }^{19} 202229$ It is possible that alcoholics may have an impaired DNA repair mechanism, and that this may be the mechanism underlying the mutagenic as well as the carcinogenic activity of ethanol in this group.

Little direct information is available to suggest that ethanol or acetaldehyde has any demonstrable effect on the cytoskeletal elements of the spindle apparatus, much of the evidence being purely circumstantial. Acetaldehyde is clearly teratogenic, and the damage induced to the developing nervous system in mouse embryos is directly related to neuroepithelial cell shape changes induced by this agent $^{13}{ }^{14}$ which are clearly mediated via the effect of this agent on the microtubules and microfilaments of the cytoskeletal system.

It is not entirely clear whether it is valid to compare the effect of ethanol on meiotic or mitotic spindle activity with the effect of anaesthetic agents on these processes. However, since ethanol and anaesthetics have many physical and chemical properties in common, and have similar physiological actions, attention is drawn to some of the experimental findings relating to members of the latter group on cell division and chromosome segregation.

Andersen ${ }^{30}$ in a detailed analysis of the effect of anaesthetics on cell division, concluded that they all inhibited mitosis by an effect on the mitotic spindle, and that this effect could be induced following exposure to clinical concentrations of these agents. Indeed, some of these agents induced errors of chromosome segregation in mammalian cells grown in tissue culture ${ }^{31}$ and were also capable of increasing the incidence of chromosomal aberrations in rat spermatogonial cells ${ }^{32}$ and mouse oocytes. ${ }^{33}$ The action of ethanol and clinical levels of anaesthetics appears to be altogether more subtle than that of many other spindle poisons (for example, cytochalasin and colchicine) on comparable stages of development in the doses usually employed. ${ }^{34-37}$

When a range of mutagenicity tests are used, the general conclusion has been drawn that modern inhalational anaesthetics are probably not mutagens. However, the anaesthetics which contain the vinyl moiety are mutagenic and are potentially carcinogenic. $^{38}$

Despite these essentially negative findings from standard mutagenicity testing studies, it has long been known that operating room personnel have a higher than expected incidence of pregnancy wastage. ${ }^{33}$ 39-42 In general, the incidence of spontaneous abortions is about twice that seen in unexposed females. As no cytogenetic information is available from analyses of the spontaneous abortus products in the exposed group, it is unclear whether the effect observed was due to an increased incidence of chromosome malsegregation in the oocytes, or due to damage to the conceptuses following fertilisation (a teratogenic effect ${ }^{33}$ ).

The incidence of congenital abnormalities was also higher in the exposed group $(9 \cdot 6 \%)$ compared to the controls $(5.9 \%, \mathrm{p}<0.01) .{ }^{39}$ The exposed group of females also had a significantly greater risk of developing cancer and hepatic and renal disease. Curiously, no increased risk of developing cancer or renal disease was observed in male anaesthetists, but a similar increased risk of developing hepatic disease was reported. No increased risk of spontaneous abortions was observed in the unexposed wives of male operating theatre personnel, but an increased risk of bearing children with congenital abnormalities was noted in the unexposed wives of male anaesthetists. The types of abnormalities reported involved most of the major organ systems. In the study by Knill-Jones et $^{4 l^{43}}$ a slight increase in the incidence of minor abnormalities was observed in association with male exposure compared to controls where neither parent was exposed, largely 
accounted for by an increase in the reporting of minor congenital abnormalities by the exposed group.

It is unclear whether anaesthetic agents affect the spindle apparatus or its precursor elements, leading to interference with normal chromosome segregation. Allison and Nunn ${ }^{44}$ have suggested that anaesthetics affect the $M$ stage of the cell cycle by depolymerising microtubules. These cytoplasmic structures are formed and disassembled during each cell division, are attached to the centromere (or kinetochore) region of the chromosomes, and are involved in the movement of chromatids to the spindle poles at anaphase. ${ }^{45}$ Indirect evidence does in fact exist which suggests that volatile anaesthetics may be capable of interfering with the mechanism which enables microtubule sub-units to associate together. ${ }^{46}$ Ultrastructural studies on cells exposed to halothane have clearly demonstrated that this agent can interfere with the assembly of mitotic microtubules, ${ }^{444748}$ and similar observations on HeLa cells arrested in mitosis following exposure to nitrous oxide indicated that the microtubule interaction necessary for prometaphase movement was in fact impaired. ${ }^{49}$ While numerous hypotheses have been proposed to explain the mitotic inhibitory effect of anaesthetics, the situation is confused by species differences in susceptibility of specific mitotic cycle stages to anaesthetic agents. ${ }^{50}$

The recent availability of immunofluorescent and immunocytochemical procedures with affinity purified antibodies to the various spindle components, ${ }^{51-54}$ used in association with the more familiar agents that act on the cytoskeletal elements, such as colchicine, cytochalasin B and D, nocodazole, etc, ${ }^{55-59}$ holds out the possibility that investigations along these lines may prove instructive in attempting to assess the underlying mechanism(s) of action of these agents on meiotic chromosome segregation.

Curiously, ethanol, benzyl alcohol, and a range of anaesthetics are also capable of inducing rodent eggs to develop parthenogenetically. ${ }^{563360-63}$ While, as indicated earlier, parthenogenetic activation per se does not appear to be associated with the induction of aneuploidy, ${ }^{6}$ the latter is observed in mouse oocytes after in vivo and in vitro activation with ethanol, ${ }^{56}$ and after in vivo activation with ethanol ${ }^{6}$ and tribromoethanol $\left(\right.$ Avertin $\left.^{33}\right)$, and may well be induced following exposure to the other agents indicated here.

It is possible that, as well as inducing parthenogenetic activation, these agents may have a residual effect on the cytoskeletal sub-units which are subsequently involved in spindle formation and activity. Such interference could lead to non- disjunction. The activity of these agents may have features in common with the effect of an intranuclear injection of anti-actin antibodies into Xenopus oocytes, where interference with chromosome condensation may be induced. ${ }^{64}$

\section{Possible clinical implications of these findings}

The recent findings from the various studies in which female mice were exposed to ethanol during either the first or the second meiotic division, and previous observations on the effect of exposure to anaesthetics and other spindle acting agents, would seem to indicate that all of these agents are capable of interfering with normal chromosome segregation. While their exact mode of action remains to be established, and it may well transpire that they all have a similar influence on the cytoskeletal elements of the spindle apparatus, it seems clear that all of these agents are capable of inducing a moderate incidence of aneuploidy under experimental (and it is hypothesised even under clinical) conditions.

Kaufman $^{65}$ has recently proposed that these substances might be the causative agents in a proportion of those cases of aneuploidy in man for which no other adequate explanation is available. Examples where the influence of maternal ageing (see below) is the likely aetiological factor, ${ }^{9}$ or when conception occurs in a subject bearing a balanced chromosome translocation, ${ }^{66}{ }^{67}$ would of course not fall into the latter category. Even excluding these subjects, their omission would have little effect on the very high incidence of spontaneous abortions more than half of which possess a numerica chromosomal defect. The latter groups almost certainly result from a non-disjunctive event which must have occurred during either the first or the second meiotic division during gametogenesis.

Relatively little information regarding the parental origin of the majority of human aneuploid states is available. However, cytogenetic analyses of spontaneous abortus material ${ }^{68-70}$ and liveborn trisomics $^{71-74}$ indicate that maternal first meiotic division errors are the most common cause of these trisomic states. The most relevant information in this regard comes from the extensive analyses that have been carried out to determine the parental origin of the extra chromosome 21 in Down's syndrome, and the origin of the extra $\mathrm{X}$ chromosome in various sex chromosome anomalies.

Chromosome polymorphism studies have recently demonstrated that the extra chromosome 21 present in Down's syndrome is in fact maternal in origin in about $77 \%$ of cases (malsegregation at meiosis I and II contributed $66.2 \%$ and $11.0 \%$, respectively), while in the remaining $23 \%$ the extra chromosome is 
paternal in origin (due to malsegregation at meiosis I and II in $13.8 \%$ and $9.0 \%$, respectively). ${ }^{74}$

Similar findings have been reported regarding malsegregation involving the $\mathrm{X}$ chromosome, from extensive studies on the inheritance of the $\mathrm{X}$ linked dominant blood group gene $\mathrm{Xg}$ in subjects with various sex chromosome anomalies. For persons with a 47,XXY karyotype, the extra chromosome was maternal in origin in $67 \%$ of cases $\left(\mathrm{X}^{\mathrm{m}} \mathrm{X}^{\mathrm{m}} \mathrm{Y}\right)$ and paternal in $33 \%\left(\mathrm{X}^{\mathrm{m}} \mathrm{X}^{\mathrm{p}} \mathrm{Y}\right)$, with the majority of errors arising during the first meiotic division. ${ }^{75-77}$ In women with Turner's syndrome $(45, X)$, it has been estimated that $77 \%$ have a maternal $X$ chromsome $\left(\mathrm{X}^{\mathrm{m}} \mathrm{O}\right)$ and $23 \%$ a paternal $\mathrm{X}$ chromosome $\left(\mathrm{X}^{\mathrm{P} O}\right),{ }^{77}$ though the mechanism of origin of this condition remains unknown. ${ }^{9}$ These findings indicate that non-disjunction is much more likely to occur at the first rather than at the second meiotic division and, possibly of greater importance in the present context, that maternal factors are apparently considerably more important than paternal ones in facilitating these malsegregation events. ${ }^{71} 78$

The aetiological factors involved in the age dependent group have received much attention, but it has yet to be established whether an increased incidence of spindle defects occurs in the oocytes ovulated by these aged females. ${ }^{79}$ It has been suggested that the increased incidence of nondisjunction observed in this group might be associated with a decrease in the chiasma frequency, as reported by Henderson and Edwards, ${ }^{80}$ though the existence of a 'production line' within the fetal ovary as proposed by these authors has yet to be unequivocally demonstrated. Furthermore, the increased occurrence of univalents at meiosis I seen in aged mice and Chinese hamster eggs does not appear to be associated with aneuploidy at metaphase II (mouse, ${ }^{81} 82$ Chinese hamster ${ }^{79}$ ).

Numerous investigators have suggested that an abnormal hormonal environment within the ovary or hormonal imbalance at the end of reproductive life might somehow predispose towards chromosomal malsegregation. ${ }^{83} 84$ Possibly an increased duration of exposure to potential hazards occurs during the first compared to the second meiotic division, though it has yet to be established whether oocytes are more vulnerable before (that is, before the resumption of meiosis) or at any particular stage during the first meiotic division once the chromosomes have condensed and become associated on the spindle apparatus.

In all probability a combination of factors is at work, with exogenous influences superimposed on the age related processes. While some of the possible age related factors are indicated above, very little has been written about the age indepen- dent influences, as until quite recently no very serious candidates had suggested themselves.

I believe that ethanol in particular, as well as other spindle acting agents, should be seriously considered as possible aetiological agents in this regard for the following reasons. Firstly, ethanol is freely available and its pharmacological actions on the metabolism of the individual ${ }^{11} 85$ are well known. Secondly, its harmful effect on fetal development has long been suspected and has recently been confirmed both clinically and experimentally in numerous animal studies, ${ }^{11} 1286-88$ and no doubts now exist that ethanol and related agents that act on the cytoskeletal elements of the spindle apparatus are potential teratogens if exposure occurs at appropriate stages of gestation. ${ }^{3} 1489-91$

It is unclear at the present time whether ethanol itself, or its primary metabolite acetaldehyde, or indeed both of these agents, are teratogenic in man. Animal studies indicate that in appropriate dosage both of these agents are probably teratogenic (ethanol, ${ }^{1291}$ acetaldehyde ${ }^{13}{ }^{4}$ ), and it is neither instructive nor appropriate in this brief discussion to attempt to distinguish which teratogenic features are more likely to be attributed to the effect of one or the other agent. Thirdly, a wide variety of studies involving both animal and plant material have now demonstrated that, under appropriate conditions, these agents are also powerful mutagens (see previous section).

While little direct evidence is available so far to implicate either ethanol or the related spindle acting agents in the induction of aneuploidy in man, I believe this hypothesis is worthy of serious consideration. In two recent large epidemiological studies, an increased risk of a spontaneous abortion was observed $^{9293}$ in drinkers, though it has yet to be established whether this finding was due to a mutagenic or possibly teratogenic effect of ethanol.

\section{Quantifying the incidence of aneuploidy at conception}

A recent study in which the chromosome constitution of almost 1000 human spermatozoa was determined indicated that the incidence of aneuploidy in this group was about $5 \% .{ }^{94}$ It is unclear what the incidence of aneuploidy is in female gametes, but it seems likely that it is equal or even higher in oocytes than in spermatozoa. ${ }^{5} \mathrm{~A}$ cytogenetic and DNA microfluorimetric analysis of in vitro fertilised human embryos at the eight cell stage has revealed that an unexpectedly high proportion were indeed aneuploid or haploid. ${ }^{96} 97$ Out of a total of 10 cleaving embryos examined, three were chromosomally abnormal, being either nullisomic or trisomic. 
Whatever the true incidence of aneuploidy at conception in man, and it may be as high as $20 \%$ of all conceptuses, ${ }^{8}$ it would be of the greatest interest to determine whether some members of the chromosome complement are more susceptible than others to undergo malsegregation events. Certainly the human spontaneous abortus data appear to indicate that the observed incidence of certain autosomal trisomies is quite different from that expected if all chromosomes had an equal chance of undergoing non-disjunction. ${ }^{98}$ Whereas monosomic subjects generally have a very limited viability, the development potential of trisomic subjects in which the same autosome is involved is very largely dependent on which extra chromosome is present. ${ }^{99} 100$ To complicate matters, it is extremely likely that the survival of a monosomic or trisomic subject also depends on its genetic constitution. Some trisomics may still be alive at the end of the first trimester, and may occasionally even survive to term, while others with the same extra chromosome present may die at or very shortly after implantation. ${ }^{101}$ Similar findings have also been reported in studies which have attempted to investigate the development potential of aneuploid and polyploid mouse embryos (aneuploidy, ${ }^{102}$ polyploidy ${ }^{103-105}$ ).

Of the various studies carried out to determine the spontaneous incidence of aneuploidy in mice, the level observed has generally been found to be extremely low, both in air dried preparations of metaphase II oocytes and spermatocytes, ${ }^{106} 107$ and at the first cleavage mitosis following fertilisation in vivo and in vitro. ${ }^{108}$ Certainly, the baseline level of aneuploidy appears to be considerably lower than the very approximate but rather high estimate made for the same condition in human oocytes, spermatozoa, and cleavage stage embryos, as indicated above.

Preliminary studies in the mouse indicate that certain autosomes may in fact be more susceptible than others to undergo spontaneous nondisjunction, with chromosome 19 being the most often involved in aneuploidy. ${ }^{109} \mathrm{By}$ contrast, the incidence of aneuploidy at conception in man, and the randomness or otherwise of the autosomes involved in this condition, will only be established when sufficient numbers of early human conceptuses have been analysed cytogenetically.

If it is valid to extrapolate from the results of the mouse studies described here to the situation in man, it would seem advisable to warn potential parents of the possible hazards of ethanol consumption (and exposure to anaesthetics) at the time of conception and, possibly more importantly, during the oocyte maturation cycle leading to ovulation if there is any likelihood that this is to be associated with conception. However, the exact risk involved of inducing an aneuploid conceptus, and its chance of survival, is extremely difficult to quantify, as both of these factors are likely to be influenced by the genetic constitution of the parents, the time of exposure, the dose and agent involved, and the age of the mother.

The work described here was supported by a grant from the National Fund for Research into Crippling Diseases (Action Research for the Crippled Child).

\section{References}

${ }^{\prime}$ Kaufman MH, Bain IM. Influence of ethanol on chromosome segregation during the first and second meiotic divisions in the mouse egg. J Exp Zool 1984;230:315-20.

${ }^{2}$ Kaufman MH, Bain IM. The development potential of ethanol-induced monosomic and trisomic conceptuses in the mouse. J Exp Zool 1984;231:149-55.

3 Kaufman MH. Ethanol-induced chromosomal abnormalities at conception. Nature 1983;302:258-60.

4 Tarkowski AK. An air-drying method for chromosome preparations from mouse eggs. Cytogenetics 1966;5:394-400.

5 Kaufman MH. The chromosome complement of singlepronuclear haploid mouse embryos following activation by ethanol treatment. J Embryol Exp Morphol 1982;71:139-54.

${ }^{6}$ Kaufman MH. Early mammalian development: parthenogenetic studies. Cambridge: Cambridge University Press, 1983.

7 Alberman ED. Creasy MR. Frequency of chromosomal abnormalities in miscarriages and perinatal deaths. $J$ Med Genet 1977;14:313-5.

${ }^{8}$ Edmonds DK, Lindsay KS, Miller JF, Williamson E, Wood PJ. Early embryonic mortality in women. Fertil Steril 1982;38:447-53.

${ }^{9}$ Bond DJ, Chandley AC. Aneuploidy. Oxford: Oxford University Press, 1983.

10 Abel EL, Dintcheff BA, Bush R. Effects of beer, wine, whiskey, and ethanol on pregnant rats and their offspring. Teratology 1981;23:217-22.

1 Colangelo W. Jones DG. The fetal alcohol syndrome: a review and assessment of the syndrome and its neurological sequelae. Prog Neurobiol 1982;19:271-314.

12 Randall CL, Riley EP. Prenatal alcohol exposure: current issues and the status of animal research. Neurobehav Toxicol Teratol 1981;3:11-115

13 O'Shea KS, Kaufman MH. The teratogenic effect of acetaldehyde: implications for the study of the fetal alcohol syndrome. J Anat 1979;128:65-76.

14 O'Shea KS, Kaufman MH. Effect of acetaldehyde on the neuroepithelium of early mouse embryos. J Anat 1981;132:10718.

15 Alvarez MR. Numerical chromosome variation in mouse spermatogonia resulting from alcohol consumption. $J$ Hered 1983;74:58.

16 Barilyak IR, Kozachuk SY. Effects of ethanol on the genetic apparatus of mammalian germ cells. Cytology and Genetics 1981;15:24-7.

17 Barthelmess A. Chemisch induzierte multipolare mitosen. Protoplasma 1957;48:546-61.

${ }^{18}$ Maguire MP. The effect of ethanol on meiotic chromosome behavior in maize. Caryologia 1976;29:41-52.

19 Obe G, Ristow H. Acetaldehyde, but not ethanol, induces sister chromatid exchanges in Chinese hamster cells in vitro. Mutat Res 1977;56:211-3.

20 Obe G, Ristow H. Mutagenic, cancerogenic and teratogenic effects of alcohol. Mutat Res 1979;65:229-59. 
${ }^{21}$ Obe G, Ristow H, Herha J. Chromosomal damage by alcohol in vitro and in vivo. In: Gross MM, ed. Alcohol intoxication and withdrawal. Vol IIIa. Biological aspects of ethanol. New York: Plenum, 1977: 47-70.

${ }^{22}$ Obe G, Ristow H, Herha J. Effect of ethanol on chromosomal structure and function. In: Majchrowicz E, Noble EP, eds. Biochemistry and pharmacology of ethanol. New York: Plenum, 1979: 659-76.

23 Badr FM, Badr RS, Asker RL, Hussain FH. Evaluation of the mutagenic effects of ethyl alcohol by different techniques. In: Gross MM, ed. Alcohol intoxication and withdrawal. Vol IIIa. Biological aspects of ethanol. New York: Plenum, 1977:25-46.

${ }^{24}$ Badr FM, Badr RS. Induction of dominant lethal mutation in male mice by ethyl alcohol. Nature $1975 ; 253: 134-6$.

25 Bregman AA. Cytogenetic effects of ethanol in human leukocyte cultures. Environ Mut Soc Newsl 1971;4:35-6.

${ }^{26}$ Reiger R, Michaelis A. Chromosomenaberrationen nach Einwirkung von Acetaldehyd auf Primärwurzeln von Vicia faba. Biol Zentralbl 1960;79:1-5.

${ }^{27}$ Sax K, Sax HJ. Radiomimetic beverages, drugs and mutagens. Proc Natl Acad Sci USA 1966;55:1431-5.

${ }^{28}$ Sax K, Sax HJ. Radiomimetic beverages and drugs. Science 1966;152:676.

29 de Torok D. Chromosomal irregularities in alcoholics. Ann NY Acad Sci 1972;197:90-100.

30 Andersen NB. The effect of CNS depressants on mitosis. Acta Anaesthesiol Scand [Suppl] 1966;22:1-36.

${ }^{31}$ Kusyk CJ, Hsu TC. Mitotic anomalies by three inhalation halogenated anesthetics. Environ Res 1976;12:366-70.

32 Coate WB, Kapp RW, Lewis TR. Chronic exposure to low concentrations of halothane-nitrous oxide: reproductive and cytogenetic effects in the rat. Anesthesiology 1979;50:310-8.

${ }^{33}$ Kaufman MH. Effect of anaesthetic agents on eggs and embryos. In: Johnson MH, ed. Development in mammals. Vol 1. Amsterdam: North-Holland, 1977:137-63.

${ }^{34}$ Edwards RG. Colchicine-induced heteroploidy in early mouse embryos. Nature 1954;174:276-7.

35 Edwards RG. Colchicine-induced heteroploidy in the mouse. I. The induction of triploidy by treatment of the gametes. $J$ Exp Zool 1958;137:317-48.

${ }^{36}$ McGaughey RW, Chang MC. Inhibition of fertilization and production of heteroploidy in eggs of mice treated with colchicine. J Exp Zool 1969;171:465-80.

${ }^{37}$ Niemierko A, Opas J. Manipulation of ploidy in the mouse. In: Daniel JC Jr, ed. Methods in mammalian reproduction. New York: Academic Press, 1978: 49-65.

38 Baden JM. Simmon VF. Mutagenic effects of inhalational anesthetics. Mutat Res 1980;75:169-89.

39 American Society of Anesthesiologists. Occupational disease among operating room personnel: a national survey. Anesthesiology 1974:41:321-40.

40 Askrog V, Harvald B. Teratogen effekt af inhalationsanaestetika. Nord Med 1970;83:498-500 (summary in English).

${ }^{41}$ Knill-Jones RP, Rodrigues LV, Moir DD. Spence AA. Anaesthetic practice and pregnancy. Controlled survey of women anaesthetists in the United Kingdom. Lancet $1972: \mathbf{i}: 1326-8$.

42 Vaisman AI. Working conditions in surgery and their effect on the health of anesthesiologists. Eksp Khir Anesteziol 1967:12:44-9 (English translation).

${ }^{43}$ Knill-Jones RP. Newman BJ, Spence AA. Anaesthetic practice and pregnancy. Controlled survey of male anacsthetists in the United Kingdom. Lancet 1975;ii:807-9.

4 Allison AC. Nunn JF. Effects of general anaesthetics on microtubules. A possible mechanism of anacsthesia. Lancet 1968:ii:1326-9.

45 McIntosh JR, Landis SC. The distribution of spindle microtubules during mitosis in cultured human cells. J Cell Biol 1971:49:468-97.
46 Laasberg LH, Hedley-Whyte J. Optical rotatory dispersion of hemoglobin and polypeptides: effect of halothane. J Biol Chem 1971:246:4886-93.

${ }^{47}$ Hinkley RE. Samson FE. Anesthetic-induced transformation of axonal microtubules. J Cell Biol 1972:53:258-63.

${ }^{48}$ Hinkley RE. Telser AG. The effects of halothane on cultured mouse neuroblastoma cells. I. Inhibition of morphological differentiation. J Cell Biol 1974;63:531-40.

49 Brinkley BR, Rao PN. Nitrous oxide: effects on the mitotic apparatus and chromosome movement in HeLa cells. $J$ Cell Biol 1973:58:96-106.

5) Jackson SH. Anesthetics and cell multiplication. Clin Anesth 1975;11:75-92.

51 Aubin JE, Weber K, Osborn M. Analysis of actin and microfilament-associated proteins in the mitotic spindle and cleavage furrow of $\mathrm{PtK} 2$ cells by immunofluoresence microscopy. Exp Cell Res 1979;124:93-109.

52 Barak LS, Yocum RR. Nothnagel EA. Webb WW. Fluorescence staining of the actin cytoskeleton in living cells with 7-nitrobenz-2-oxa-1,3-diazole-phallacidin. Proc Natl Acad Sci USA 1980:77:980-4.

53 Lazarides E. Immunofluorescence studies on the structure of actin filaments in tissue culture cells. $J$ Histochem Cytochem 1975;23:507-28.

${ }^{54}$ Paulin D. Babinet C. Weber K. Osborn M. Antibodies as probes of cellular differentiation and cytoskeletal organization in the mouse blastocyst. Exp Cell Res 1980;130:297-304.

55 Weber K. Rathke PC. Osborn M. Franke WW. Distribution of actin and tubulin in cells and in glycerinated cell models after treatment with Cytochalasin B (CB). Exp Cell Res 1976;102:285-97.

56 Brown SS, Spudich JA. Cytochalasin inhibits the rate of elongation of actin filament fragments. J Cell Biol 1979:83:65762 .

57 Hartwig JH, Stossel TP. Cytochalasin B and the structure of actin gels. J Mol Biol 1979;134:539-53.

s8 MacLean-Fletcher S, Pollard TD. Mechanism of action of cytochalasin B on actin. Cell 1980:20:329-41.

59 Maro B. Bornens M. The centriole-nucleus association: effect of cytochalasin B and nocodazole. Biol Cell 1980:39:287-90.

6) Austin CR, Braden AWH. Induction and inhibition of the second polar division in the rat egg and subsequent fertilization. Aust J Biol Sci 1954:7:195-210.

${ }^{61}$ Braden AWH. Austin CR. Reactions of unfertilized mouse eggs to some experimental stimuli. Exp Cell Res 1954:7:277-80.

62 Cuthbertson KSR. Parthenogenetic activation of mouse oocytes in vitro with ethanol and benzyl alcohol. $J$ Exp Zool 1983;226:311-4

${ }^{63}$ Kaufman MH. Parthenogenetic activation of mouse oocytes following avertin anaesthesia. J Embryol Exp Morphol 1975;33:941-6.

${ }^{64}$ Rungger D, Rungger-Brändle E, Chaponnier C, Gabbiani G. Intranuclear injection of anti-actin antibodies into Xenopus oocytes blocks chromosome condensation. Nature 1979;282:320-1.

${ }^{65}$ Kaufman MH. The influence of alcohol on female germ cells. BioEssays 1984;1:117-20.

${ }^{6}$ Hamerton JL. Human cytogenetics. Vol 1. General cytogenetics. New York: Academic Press, 1971.

${ }^{67}$ Penrose LS. Smith GF. Down's anomaly. London: Churchill. 1966.

${ }^{68}$ Hassold TJ, Chen N, Funkhouser J, et al. A cytogenetic study of 1000 spontaneous abortions. Ann Hum Genet 1980:44: 151-78.

${ }^{69}$ Hassold TJ, Jacobs P, Kline J, Stein Z, Warburton D. Effect of maternal age on autosomal trisomies. Ann Hum Genet 1980;44:29-36.

${ }^{70}$ Hassold TJ, Matsuyama A. Origin of trisomies in human spontaneous abortions. Hum Genet 1979:46:285-94. 
71 Jacobs PA, Hassold TJ. The origin of chromosome abnormalities in spontaneous abortions. In: Porter IH, Hook EB, eds. Human embryonic and fetal death. New York: Academic Press, 1980:289-98.

72 Magenis RE, Overton KM, Chamberlin J, Brady T, Lovrien E. Parental origin of the extra chromosome in Down's syndrome. Hum Genet 1977;37:7-16.

${ }^{73}$ Mikkelsen M, Hallberg A, Poulsen H. Maternal and paternal origin of extra chromosome in trisomy 21. Hum Genet 1976;32:17-21

${ }^{74}$ Mikkelsen M, Poulsen H, Grinsted J, Lange A. Nondisjunction in trisomy 21 . Study of chromosomal heteromorphisms in 110 families. Ann Hum Genet 1980;44:17-28.

75 Race RR, Sanger R. Xg and sex-chromosome abnormalities. Br Med Bull 1969;25:99-103.

76 Sanger R, Tippett P, Gavin J. Xg groups and sex abnormalities in people of northern European ancestry. J Med Genet 1971;8:417-26.

77 Sanger R, Tippett P, Gavin J, Teesdale P, Daniels GL. Xg groups and sex chromosome abnormalities in people of northern European ancestry: an addendum. J Med Genet 1977;14:210-1.

78 de Boer P, Tates AD. Radiation-induced nondisjunction. In: Radiation-induced chromosome damage in man. New York: Alan R Liss, 1983:299-325.

${ }^{79}$ Sugawara S, Mikamo K. Absence of correlation between univalent formation and meiotic nondisjunction in aged female Chinese hamsters. Cytogenet Cell Genet 1983;35:34-40.

80 Henderson SA, Edwards RG. Chiasma frequency and maternal age in mammals. Nature 1968;218:22-8

81 Polani PE, Jagiello GM. Chiasmata, meiotic univalents, and age in relation to aneuploid imbalance in mice. Cytogenet Cell Genet 1976;16:505-29.

82 Speed RM. The effects of ageing on the meiotic chromosomes of male and female mice. Chromosoma 1977;64:241-54.

83 Crowley PH, Gulati DK, Hayden TL, Lopez P, Dyer R. A chiasma-hormonal hypothesis relating Down's syndrome and maternal age. Nature 1979;280:417-9.

84 Rundle A, Coppen A, Cowie V. Steroid excretion in mothers of mongols. Lancet $1961 ;$;i:846-8.

${ }^{85}$ Morgan MY. Sex and alcohol. Br Med Bull 1982;38:43-8.

86 Lemoine P, Harrousseau M, Borteyru JP, Menuet JC. Les enfants de parents alcooliques. Anomalies observees. A propos de 127 cas. Quest Med 1968;21:476-82.

87 Pratt OE. Alcohol and the developing fetus. $\mathrm{Br}$ Med Bull 1982;38:48-52.

88 Ulleland CN. The offspring of alcoholic mothers. Ann NY Acad Sci 1972;197:167-9.

89 Brown NA, Goulding EH, Fabro S. Ethanol embryotoxicity: direct effects on mammalian embryos in vitro. Science 1979;206:573-5.

90 Sulik KK, Johnston MC. Sequence of developmental alterations following acute ethanol exposure in mice: craniofacial features of the fetal alcohol syndrome. Am J Anat 1983;166:257-69.

91 Sulik KK. Critical periods for alcohol teratogenesis in mice, with special reference to the gastrulation stage of embryogenesis. In: Porter R, O'Connor M, Whelan J, eds. Mechanisms of alcohol damage in utero. London: Pitman, 1984:124-41.
92 Harlap S, Shiono PH. Alcohol, smoking, and incidence of spontaneous abortions in the first and second trimester. Lancet 1980;ii:173-6.

${ }^{93}$ Kline J, Shrout P, Stein Z, Susser M, Warburton D. Drinking during pregnancy and spontaneous abortion. Lancet 1980;ii: $176-80$.

${ }^{94}$ Martin RH, Lin CC, Balkan W, Burns K. Direct chromosomal analysis of human spermatozoa: preliminary results from 18 normal men. Am J Hum Genet 1982;34:459-68.

95 Golbus MS. Chromosome aberrations and mammalian reproduction. In: Mastroianni L, Biggers JD, eds. Fertilization and early embryonic development in vitro. New York: Plenum Press, 1981:257-72.

9 Angell RR, Aitken RJ, van Look PFA, Lumsden MA, Templeton AA. Chromosome abnormalities in human embryos after in vitro fertilization. Nature 1983;303:336-8.

97 Angell RR, Aitken RJ, van Look PFA, Lumsden MA, Templeton AA. Chromosome anomalies in human preimplantation embryos. J Embryol Exp Morphol [Suppl] 1984;82:193.

98 Ford CE. The time in development at which gross genome unbalance is expressed. In: Balls M, Wild AE, eds. The early development of mammals. Cambridge: Cambridge University Press, 1975:285-304.

99 Boué JG. Boué A. Chromosomal anomalies in early spontaneous abortion. (Their consequences on early embryogenesis and in vitro growth of embryonic cells.) Curr Top Pathol 1976;62:193-208.

100 Epstein CJ. The effects of chromosomal aneuploidy on early development: experimental approaches. In: Mastroianni L, Biggers JD, eds. Fertilization and early embryonic development in vitro. New York: Plenum Press, 1981:273-81.

101 Gropp A. Value of an animal model for trisomy. Virchows Arch (Pathol Anat) 1982;395:117-31.

102 Gropp A, Putz B, Zimmermann U. Autosomal monosomy and trisomy causing developmental failure. Curr Top Pathol 1976;62:177-92.

${ }^{103}$ Niemierko A. Postimplantation development of CB-induced triploid mouse embryos. J Embryol Exp Morphol 1981;66:81-9.

104 Wróblewska J. Developmental anomaly in the mouse associated with triploidy. Cytogenetics 1971;10:199-207.

105 Wróblewska J. Spontaneous triploidy and tetraploidy in inbred strain (sic) of mice and their crosses. PhD thesis, Warsaw University, 1978 (cited by Niemierko, 1981).

106 Hansmann I, Probeck HD. Detection of nondisjunction in mammals. Environ Health Perspect 1979;31:161-5.

107 Nijhoff JH, de Boer P. Spontaneous meiotic non-disjunction in mammals. A study evaluating the various experimental approaches. Genetica 1981;56:99-121.

${ }^{108}$ Fraser LR, Maudlin I. Analysis of aneuploidy in first cleavage mouse embryos fertilized in vitro and in vivo. Environ Health Perspect 1979;31:141-50.

109 Martin-DeLeon PA, Boice ML. Spontaneous heteroploidy in one-cell mouse embryos. Cytogenet Cell Genet 1983;35:57-63.

Correspondence and requests for reprints to Professor M H Kaufman, Department of Anatomy, University Medical School, Teviot Place, Edinburgh EH8 9AG. 